\title{
Set and word abstractness-concreteness shift in paired-associate learning
}

A. DAN YARMEY AND KEITH A. THOMAS

WATERLOO LUTHERAN UNIVERSITY
Ss learned two separate PA lists of abstract and concrete nouns, differing in rated imagery. Half of the $S$ s learned first the abstract pairs then shifted to concrete while the remainder received first concrete pairs then abstract. Imaginal and verbal mediational sets were also investigated. Learning was consistently superior with concrete nouns. Imaginal set facilitated concrete noun learning and verbal set interfered with abstract PA learning. The data provided further support for a mediating-imagery hypothesis.

Paivio (1963) has suggested a metaphorical hypothesis in paired-associate (PA) learning in which stimulus items are assumed to function as "conceptual pegs" for their associates; the efficiency of words as pegs depending on their capacity to evoke images (conditioned sensations cf. Mowrer, 1960, Ch. 5), which could mediate response recall. Several studies support this hypothesis (Paivio, 1965; Paivio \& Yarmey, 1966; Paivio, Yuille, \& Smythe, 1965; Paivio \& Olver, 1964; Yarmey \& Paivio, 1965).

McNulty (1966) has shown that subjects (Ss) who were instructed to use mediators were facilitated in PA learning. Effects of instructions to mediate on abstract and concrete noun PA lists have yet to be determined and were investigated in the present study. In order to study the validity of the "concreteness" effect, the experiment also considered the effects of shift in presentation of abstract and concrete lists during learning. Method

Two lists of 10 PAs were used. One list consisted of abstract-abstract nouns, the other, concrete-concrete nouns. The words were selected from ones on which meaningfulness $(\underline{m})$ scores and imagery (I) scores (mean ratings of the ease with which nouns elicit sensory images) were available from previous research (Paivio, 1965). All concrete nouns refer to denotable objects whereas abstract nouns do not. Examples of concrete words are: elephant, ambulance, and mosquito. Abstract examples are: confidence, economy, and opinion. The Thorndike-Lorge (1944) word count indicates that all the words are highly familiar; the abstract words being slightly more frequent than concrete. The lists were equated for $\underline{m}$ (concrete $\bar{X}=10.53$; abstract $\bar{X}=10.49$ ) but all the concrete nouns exceeded the abstract in rated imagery (concrete $\vec{X}:=1.13$; abstract $\overline{\mathrm{X}}=3.12) .^{1}$

Sixteen undergraduates ( 8 males and 8 females) were run in four separate groups: Concrete, Concrete Set, Abstract, and Abstract Set. The PAs were presented aurally by a tape recorder. The recall method was followed. For each list there were four study trials (both the stimulus and response members of the PA presented) alternating with four recall trials (stimulus items presented alone). Eight randomizations of the position of items on both study and recall trials were made to prevent serial learning. At the completion of recall trial four, the lists were shifted (concrete to abstract, abstract to concrete) and Ss were told to listen and learn a new list of pairs of words.

To create mediational sets, one of the concrete groups was instructed to try to visualize (i.e., make "mental pictures") a relationship between the paired words while one of the abstract groups wasurged to try to form silent verbal chains connecting the words of each pair. Examples of imaginal and verbal mediation were given. The set was only introduced before trial one and was not repeated during the shift.

The PAs were read in a monotone approximately 2 sec. apart during the study periods while the stimulus words were spoken at 10-sec. intervals during recall. A 10-sec. intertrial interval and between lists interval was employed. Ss recorded their responses on an eight page booklet, each page representing one trial. The numbers, 1-10, appeared in a column along the ed 5 e of each page showing where responses were to be written. To aid the recording of responses the guide number was read aloud immediately before the presentation of each stimulus during recall.

\section{Results}

Figure 1 presents the performance curves of the four treatments. 2

Pre-shift trials. The analysis of variance with set, concreteness, and trials serving as predictors, indicated

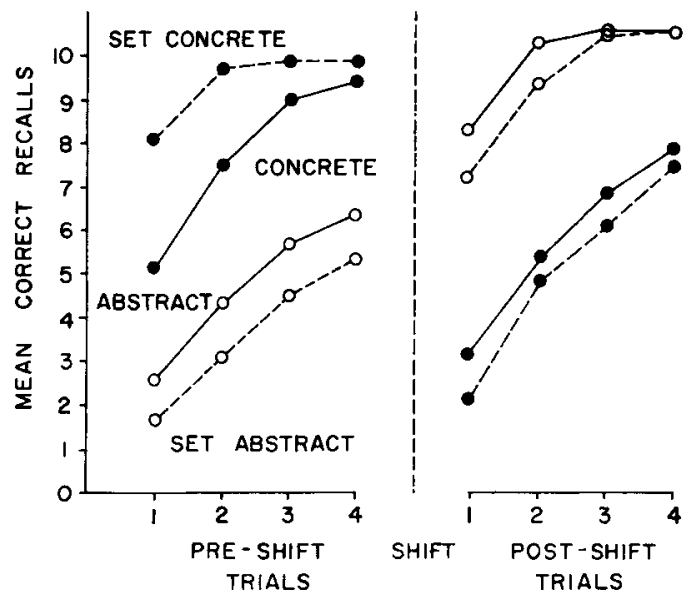

Fig. 1. Mean correct recalls as a function of set and word abstractness-concreteness shift in PA learning. 
that the concrete-abstract difference was significant $(\mathrm{F}=88.80, \mathrm{df}=1 / 60, \mathrm{p}<.001)$ and performance increased with practice (trials, $F=96.46, \mathrm{df}=3 / 180, p<.001$ ). Set was not a significant main effect. The interaction, however, of set by concreteness $(F=9.45, \mathrm{df}=1 / 60$, $\mathrm{p}<.01$ ), revealed that the effect of set differed according to type of material. There was a positive effect with the Concrete Set group and a negative effect with the Abstract Set group as shown by the figure. The interaction of set by trials $(F=4.90, \mathrm{df}=3 / 180, \mathrm{p}<.01)$ and concreteness by trials $(F=2.78, \mathrm{df}=3 / 180, \mathrm{p}<.05)$, indicated that set and type of lists had a significant effect on learning rate. All other interactions were nonsignificant.

Post-shift trials. The results were analyzed using the same variables as for the pre-shift data. It should be noted that the Concrete groups on pre-shift trials were now given an abstract PA list while the Abstract groups were given concrete pairs. A significant difference was again found for the concrete-abstract variable ( $F=$ 113.26, $\mathrm{df}=1 / 60, \mathrm{p}<.001)$ and trials $(\mathrm{F}=132.31, \mathrm{df}=$ $3 / 180, p<.001)$. The only interaction to show a significant effect was concreteness by trials ( $F=19.43$, $\mathrm{df}=3 / 180, p<.01)$. Although non-significant, the figure shows that set conditions were inferior in both concrete and abstract PA learning, indicating that the inappropriate set on post-shift trials may have caused interference.

\section{Discussion}

The results add further support to Paivio's mediatingimagery hypothesis. High imagery, concrete nouns were better learned than low-imagery, abstract nouns in both shift conditions. Since the stimulus and response elements had been controlled for $\underline{m}$ but varied in both $I$ and concreteness, one cannot attribute the effect solely to imagery. However, in light of the study by Paivio et al (1965), in which imagery under some conditions was shown to be independent of concreteness but facilitated learning, it is difficult to disregard the possibility of a nonverbal symbolic mediating process.

Set conditions on pre-shift trials showed a positive effect with concrete nouns and a negative effect with abstract. It was assumed that the instructions to use imaginal and verbal mediators for concrete and abstract nouns, respectively, would be most appropriate for the different materials. Paivio et al found that Ss retrospectively reported using imagery to link concrete nouns and verbal mediators to link abstract nouns. If one accepts the assumption that Ss in the Concrete groups did use imagery as mediators and since McNulty (1966) has demonstrated the effectiveness of set in PA learning, the significance of the variable, imagery, increases in validity. The failure to find a positive effect as well for set on abstract nouns, in fact, a negative effect was found, was surprising, and no explanation can be offered.

The present study does not indicate whether the effects of shift and set occurred equally on both the stimulus and response sides of the PA lists. This problem is currently being investigated.

\section{References}

McNulty, J. A. The effects of "instructions to mediate" upon paired-associate learning. Psychon. Sci. 1966, 4, 61-62.

Howrer, O. H. Learning theory and the symbolic processes. New York: Wiley, 1960.

Paivio, A. Learning of adjective-noun paired-associates as a function of adjective-noun word order and noun abstractness. Canad. J. Psychol., 1963, 17, 370-379.

Paivio, A. Abstractness, imagery, and meaningfulness in pairedassociate learning. J. verbal Learn. verbal Bchav. 1965, 4, 32-38.

Paivio, A., \& Olver, M. Denotative-generality, imagery, and meaningfulness in paired-associate learning of nouns. Psychon. Sci., 1964, 1, 183-184

Paivio, A., \& Yarmey, A. D. Pictures versus words as stimuli and responses in paired-associate learning. Psychon. Sci., 1966. $5,235-236$.

Paivio, A., Yuille, J. C., \& Smythe, P. C. Stimulus and response abstractness, imagery, and meaningfulness, and reported mediators in paired-associate learning. Research Bull. No. 2, Oct. 1965. University of Western Ontario, London, Canada.

Thorndike, E. L., \& Lorge, 1. The teacher's word book of 30,000 words. New York: Bureau of Pub., Teacher's College, Columbia University, 1944.

Yarmey, A. D., \& Paivio, A. Further evidence on the effects of word abstractness and meaningfulness in paired-associate learning. Psychon. Sci., 1965, 2, 307-308.

\section{Notes}

1. Low imagery scores represent greater ease of image arousal. 2. Kalman Csapo drew the figure. 